times at a hectic pace. To be listed among top global universities, premier Indian institutions should receive support to become multidisciplinary and increase their number of faculty. If faculty at 50 research institutions (e.g., IITs and central universities) can be increased to more than I,000, this could have an impact on global rankings. In addition, India could experiment with creating a few megainstitutions by merging existing universities, colleges, and research labsan approach Australia took a few decades ago with remarkable success, and also pursued in France.

To enter world rankings, support for research will have to increase substantially. For this, two initiatives can help. First, top institutions could be provided with committed, multiyear research funding based on past performancean approach that Australia and the United Kingdom follow with great results. Second, research project funding by agencies needs to increase dramatically and be accessible to all research universities - whether private or government. Many advanced countries invest over 20 percent of their public R\&D expenditure in the university sector. In India, less than 4 percent of the government $R \& D$ expenditure goes to universities. The distribution of R\&D funding must progressively move toward more support for research in universities.

It must be emphasized that sufficient size and funding alone will not automatically ensure a position in global rankings. In addition, universities in the top league will need to have strong systems to encourage and support high quality research, recruit the best talent and promote meritocracy, build a vibrant innovation culture, have strong leadership and governance, etc.

It should also be kept in mind that being in the top 200 globally is a zero-sum game. For an Indian institution to be in this group, a university currently at the top will have to drop out. As many countries currently are eager to be represented among this elite group, competition is every year getting tougher, and changes need to happen at a faster pace.

In cooperation with the American Council on Education, CIHE has published International Briefs for Higher Education Leaders no. 8 on Attainment and Inclusion in Higher Education. This annual brief was edited by Robin Matross Helms and Lucia Brajkovic from ACE and Laura E. Rumbley from the European Association for International Education, and contains I3 international perspectives and four case studies from different countries around the globe. It examines sustained efforts undertaken to ensure equitable opportunities for degree attainment for all students, including underserved or traditionally marginalized populations.

\section{Concentration of Institutions and Urban Bias in India}

\section{N.V. Varghese and Jinusha Panigrahi}

N.V. Varghese is vice-chancellor and director of the Center for Policy Research in Higher Education, National Institute of Educational Planning and Administration (CPRHE/NIEPA), New Delhi, India. E-mail: nv.varghese@niepa.ac.in. Jinusha Panigrahi is assistant professor at CPRHE/NIEPA. E-mail: jinusha@niepa.ac.in.

$\mathrm{T}$ The massification of higher education is in general associated with improved access and reduced inequalities. Empirical evidence in India shows that the expansion of the system is accompanied by various forms of inequalities. Traditionally, the higher education sector in India has grown slowly, with low enrollment rates. This century witnessed a dramatic turnaround when the sector experienced accelerated growth leading to the massification of the sector. In 20I7-20I8, India had more than 900 universities, 4I, 000 colleges, 36.6 million students, and a gross enrollment ratio (GER) of 25.8 percent. Regional inequalities in higher education development have widened and social inequalities continue to be high, while gender inequalities are narrowing down. Based on a study conducted by the Centre for Policy Research in Higher Education at the National Institute of Educational Planning and Administration (CPRHE/ NIEPA), this article discusses some important features of concentration and urban bias in higher education development in India. This is relevant for higher education policy in this country and in other countries around the world with similar issues.

\section{Urban Bias in Higher Education Development}

Any economic growth process produces concentration and diffusion effects. Concentration effects through unequal resource allocations lead to regional polarization. Diffusion effects, through their forward and backward linkages, result in spread development. Since knowledge economies rely on universities for knowledge production and the training of knowledge workers, a dispersed growth of universities help develop research capacities to support faster growth and a balanced regional development.

As in many countries, the development of higher education in India has an urban bias. The first group of universities were established in 1857 in the Presidencies (cities) of Calcutta, Bombay, and Madras. The establishment of higher education institutions (HEIs) in the postindependence period also favored urban locations. The universities and HEIs established in the I950s and I960s were mostly in 
urban or semiurban locations. The establishment of rural institutes and agricultural universities was an exception to this trend.

In India, there is a positive correlation between localities that are poorly endowed in terms of HEIs and low enrollment. In the I970s, public policy paid special attention to the establishment of HEIs in rural, underdeveloped, and hilly areas to reduce rural-urban imbalances in higher education development. However, the proliferation of private HEIs (PHEIs) offset public initiatives to reduce regional inequalities. With the decline in public investment in higher education in the I980s and onward, the private sector became active in establishing HEIs in urban and semiurban locations, especially in professional and technical subjects.

\section{Concentration on Higher Education Institutions}

The authors developed a concentration ratio measure to assess inequalities in the distribution of HEIs. This measure takes into account age group (18-23); total enrollments in higher education; number of institutions per region; average size of institutions; and GER.

Regional disparities in the distribution of HEIs have widened. For example, the number of institutions per I00,000 inhabitants varies from seven in Bihar to 56 in Telangana. While the number of HEIs have increased in all

\section{Regional inequalities in higher educa- tion development have widened and social inequalities continue to be high, while gender inequalities are narrowing down.}

states, the rates of growth vary. In other words, the increasing regional inequalities in the provision of higher education are due more to variations in the rates of growth of institutions than in an absence of growth.

In most states, the concentration ratio is positively correlated with the GER and inversely correlated with the average size of institutions. These findings imply that states with a high concentration of HEIs have larger institutions and higher enrollment in each institution. This is not surprising, given the high and positive correlation (0.84) between the number of HEIs and higher secondary schools whose graduates create increased social demand for higher education.

A further analysis indicates that states that have a higher share of private, unaided institutions also have a higher density of HEIs. The increase in the number of PHEIs has contributed to an increased concentration of HEIs in the states. On the other hand, states that predominantly depend on public institutions a have lower concentration of HEIs. These trends show that the market response to growing social demand for higher education is a reason for increased concentration of HEIs in urban areas.

The analysis based on 635 districts found that there is high concentration of HEIs in some districts compared to a low availability of HEIs in other districts. The analysis showed I7 districts without a single higher education institution and I9I districts with a very low concentration ratio- these districts must pay urgent attention to the need to open new HEIs. Fifty-four districts must establish general HEIs, I2I districts need technical HEIs, and I6 districts require both types. Right behind, some 293 districts are also in need of establishing HEIs to cover the needs of their populations.

\section{Utility of Concentration Ratios}

The overall conclusion from the analysis is that there is concentration of HEIs and an urban bias in higher education development in India. Nearly 75 percent of the districts are deprived of HEIs, either partially or fully. Establishing new HEIs in line with the prioritization indicated by the concentration ratio may help the country to level off existing inequalities in the provision of higher education and to reach a more balanced regional coverage.

\section{The Internationalization}

\section{Agenda of African Universi- ties in the Next Decade}

\section{Harris Andoh and Jamil Salmi}

Harris Andoh is a research policy evaluation expert at Tshwane University of Technology, Pretoria, South Africa, and at the Science and Technology Policy Research Institute (STEPRI) of the Council for Scientific and Industrial Research (CSIR), Accra, Ghana. E-mail: andoharris@gmail.com. Jamil Salmi is a global tertiary education expert and a research fellow at the Center for International Higher Education, Boston College, US. E-mail: jsalmi@tertiaryeducation.org.

$\mathrm{T}$ The internationalization mission of African universities has evolved from initial failed attempts to more recent efforts to ground internationalization in the strategic vision of the institution. In this article, we review how internation- 